\title{
Regulating dynamin dynamics during endocytosis
}

\section{Anna C. Sundborger and Jenny E. Hinshaw*}

Address: Laboratory of Cell and Molecular Biology, National Institute of Diabetes and Digestive and Kidney Diseases, NIH, Bethesda, MD, 20892, USA

*Corresponding author: Jenny E. Hinshaw (jennyh@helix.nih.gov)

Fl000Prime Reports 2014, 6:85 (doi:10.12703/P6-85)

All Fl000Prime Reports articles are distributed under the terms of the Creative Commons Attribution-Non Commercial License (http://creativecommons.org/licenses/by-nc/3.0/legalcode), which permits non-commercial use, distribution, and reproduction in any medium, provided the original work is properly cited.

The electronic version of this article is the complete one and can be found at: http://fl000.com/prime/reports/b/6/85

\begin{abstract}
Dynamin is a large GTPase that mediates plasma membrane fission during clathrin-mediated endocytosis. Dynamin assembles into polymers on the necks of budding membranes in cells and has been shown to undergo GTP-dependent conformational changes that lead to membrane fission in vitro. Recent efforts have shed new light on the mechanisms of dynamin-mediated fission, yet exactly how dynamin performs this function in vivo is still not fully understood. Dynamin interacts with a number of proteins during the endocytic process. These interactions are mediated by the C-terminal proline-rich domain (PRD) of dynamin binding to $\mathrm{SH} 3$ domain-containing proteins. Three of these dynamin-binding partners (intersectin, amphiphysin and endophilin) have been shown to play important roles in the clathrinmediated endocytosis process. They promote dynamin-mediated plasma membrane fission by regulating three important sequential steps in the process: recruitment of dynamin to sites of endocytosis; assembly of dynamin into a functional fission complex at the necks of clathrin-coated pits (CCPs); and regulation of dynamin-stimulated GTPase activity, a key requirement for fission.
\end{abstract}

\section{Introduction}

The large GTPase dynamin belongs to a family of proteins that mediate various membrane-remodeling events in the cell. Dynamin is best characterized by its role in plasma membrane fission during clathrin-mediated endocytosis [1]. Other members of the dynamin family mediate additional membrane fission and fusion events in the cell, including the fission and fusion of mitochondrial membranes (dynamin-related protein 1 [Drp1], optical atrophy 1 [Opa1] and mitofusin), peroxisome fission (Drp1), and endoplasmic reticulum fusion (atlastin) [2]. All members of the dynamin family contain a G domain that binds and hydrolyses GTP and a stalk domain that promotes self-assembly $[3,4]$. Dynamin also contains a pleckstrin homology (PH) domain and a PRD. These unique domains almost certainly convey the specific function of dynamin in the cell. The $\mathrm{PH}$ domain preferentially binds phosphatidylinositol 4,5-bisphosphate $\left(\mathrm{PIP}_{2}\right)$ [5], a lipid enriched in the plasma membrane [6], which is believed to function as a key signaling molecule for the recruitment and assembly of the clathrin machinery [7-9]. The PRD provides a platform for dynamin partners to bind via SH3-binding motifs [10-14]. In recent years, a concerted effort has been made to identify the molecular mechanisms that govern dynamin's role in membrane fission. This review will discuss current models of how the GTP hydrolysis cycle of dynamin drives fission during clathrin-mediated endocytosis, and how dynamin-binding partners may regulate this process.

\section{Dynamin recruitment to sites of endocytosis SH3 domain-containing endocytic accessory proteins} The recruitment of dynamin to sites of endocytosis is dependent on its PRD [12]. Dynamin interacts with a number of endocytic accessory proteins through several SH3-binding motifs located in the PRD [10-14]. Three SH3 domain-containing binding partners of dynamin have been shown to play a role in recruiting dynamin to CCPs on the plasma membrane, intersectin [15-19], amphiphysin [20-25] and endophilin [24,26] (Figure 1).

SH3 domain-containing proteins are the bestcharacterized members of a growing family of proteinprotein interaction modules [27]. They recognize 
Figure I. SH3 domain-containing binding partners of dynamin

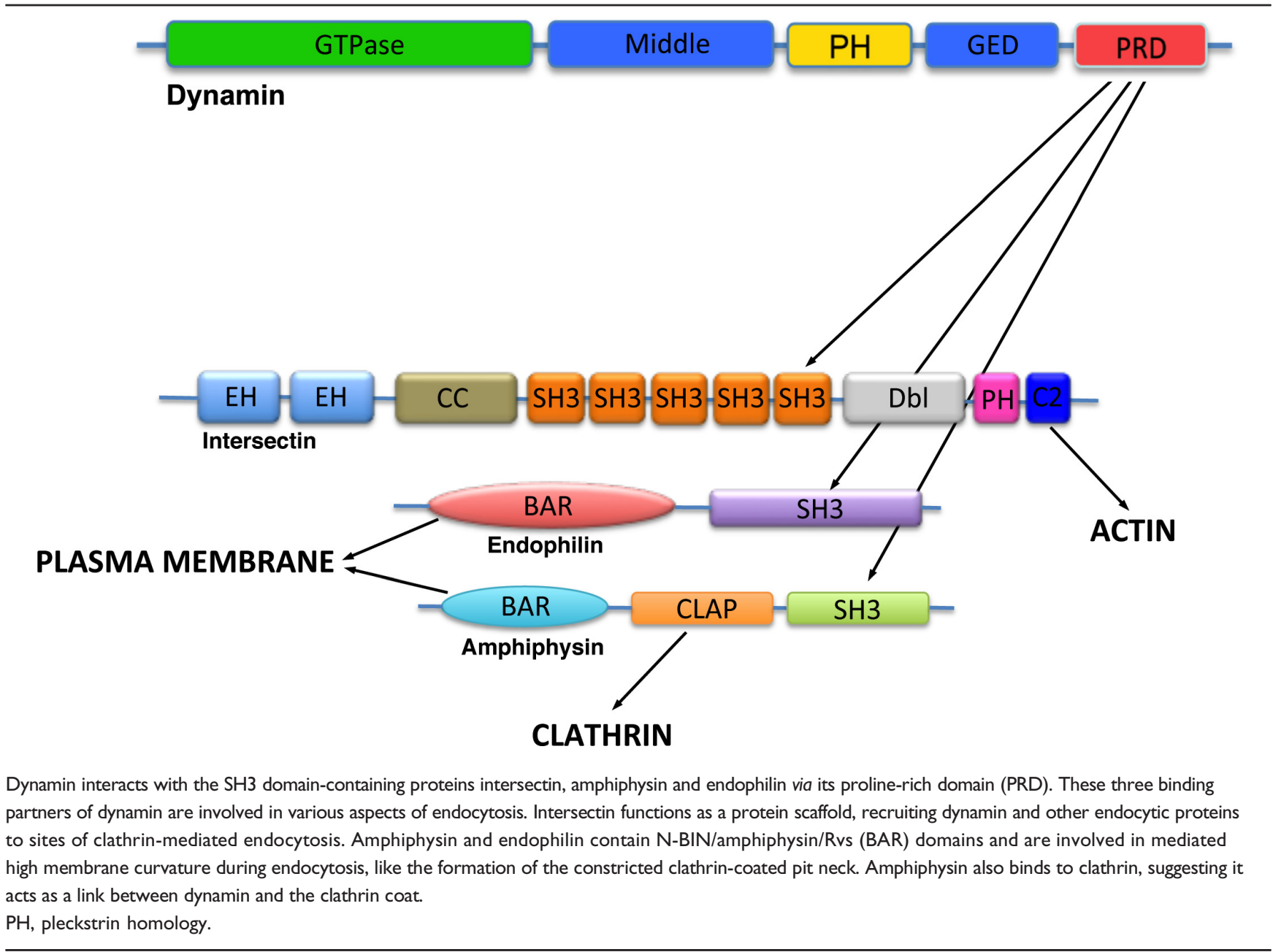

proline-rich sequences in a large number of otherwise structurally and functionally diverse proteins. SH3 domains contain a negatively charged pocket that binds proline-rich sequences. These interactions have fairly low affinity and moderately low specificity [28]. It is not uncommon for proteins to have several SH3 domains linked in tandem, suggesting that SH3 domain-containing proteins are capable of mediating the formation of large protein complexes with high rates of assembly and disassembly, like the endocytic machinery. For example, the dynamin-binding partner intersectin contains several SH3 domains that interact with dynamin $[15,19,29-32]$, synaptojanin [33], and the actin network [29,31,34,35].

\section{Intersectin, an endocytic scaffolding protein}

In neuronal cells, clathrin-mediated endocytosis is required for synaptic membrane recycling. Upon stimulation of nerve terminals, the $\mathrm{Ca}^{2+}$-dependent phosphatase calcineurin dephosphorylates dynamin and other endocytic proteins (amphiphysin, epsin, eps15 and synaptojanin)
[36-38], which leads to their recruitment to sites of vesicle recycling $[15,19,26,39]$. In neuromuscular junctions of Drosophila, the intersectin homologue Dap160 has been shown to regulate this recruitment of dynamin and other endocytic proteins (endophilin, synaptojanin and AP180) [16-19]. Intersectin also interacts with components of the actin network $[29,31,34,35]$, which suggests that it functions as a scaffold to regulate the recruitment of both the endocytic machinery and the actin network to sites of endocytosis. It has also been shown that actin may be directly involved in regulating the endocytic process [40-45], and recent studies show that its function is tightly coupled to that of dynamin $[46,47]$.

\section{Assembly of dynamin at the necks of coated pits BIN/amphiphysin/Rvs domain-containing proteins and dynamin assembly \\ Dynamin co-localizes with intersectin, endophilin, and amphiphysin on clathrin-coated budding vesicles $[16,19,45,48-51]$. In addition to SH3 domains, endophilin}


and amphiphysin also contain BIN/amphiphysin/Rvs (BAR) domains. BAR domain-containing proteins mediate membrane sensing and curvature via homodimerization [52-54]. Depending on the shape of the BAR domain dimer, these proteins sense and promote either positive ( $\mathrm{N}$ - and $\mathrm{F}$ [FCH]-BAR proteins) [55-60], or negative curvature (I[inverse]-BAR proteins) [61,62]. BAR domains bind the membrane via electrostatic interactions with lipid head groups. N-BAR proteins contain an amphiphatic helix in their N-terminus (hence the name N-BAR). This helix inserts into the lipid bilayer and may play a role in sensing membrane curvature $[55,57]$. N-BAR proteins promote high curvatures $[55,57,59,60]$, while proteins containing F-BAR domains have been shown to stabilize more shallow membrane deformations $[56,63,64]$. It has been shown that the F-BAR proteins FCHo (F-BAR domain-containing Fer/Cip4 homology domain-only protein) [65] and FBP17 (formin binding protein 17) [66] are recruited at early stages of CCP formation along with the clathrin adaptors epsin $[67,68]$ and AP180 $[68,69]$, suggesting that they mediate initial membrane curvature at the sites of clathrin assembly. The membrane neck may then be subsequently narrowed and stabilized by the higher curvature-generating N-BAR proteins endophilin and amphiphysin. This suggests that, following the recruitment to the sites of endocytosis, SH3/BAR domain-containing binding partners of dynamin are continuously involved in promoting dynamin-mediated fission.

BAR domain proteins as membrane templates for dynamin Once recruited to sites of endocytosis, dynamin must assemble on the necks of CCPs to mediate the release of vesicles. Proper assembly is crucial for dynamin to perform its function. It has been shown that dynamin preferentially binds to high membrane curvature, such as lipid nanotubes [70], and the necks of CCPs $[15,26,39,71,72]$. In nerve terminals, endophilin and amphiphysin both co-localize with dynamin on constricted CCPs [26]. Injections of antibodies against the BAR domain of endophilin into nerve terminals caused an accumulation of shallow CCPs upon stimulation, and subsequent inhibition of synaptic vesicle recycling, supporting the idea that BAR proteins mediate curvature during CCP formation [73]. Furthermore, when interactions between dynamin and endophilin were selectively perturbed, dynamin failed to localize to CCP necks, despite recruitment to sites of endocytosis [26]. These nerve terminals further failed to maintain synaptic vesicle recycling as evidenced by the accumulation of CCPs, an indication of an inhibition of membrane fission. In cells, the knockdown of both amphiphysin and endophilin decreased the recruitment of dynamin to the plasma membrane and inhibited transferrin uptake [74]. It was further shown in vitro that endophilin facilitated the binding of dynamin to liposomes [26] and clustering of dynamin to giant unilamellar vesicles (GUVs) [74]. Both endophilin and amphiphysin also promoted dynaminmediated vesiculation from large lipid reservoirs on silica beads [75]. In addition, endophilin promoted recruitment of the dynamin mutant I533A, which fails to bind lipid bilayers, suggesting SH3/BAR protein-mediated curvature can overcome the lipid-binding defects of this mutant, and rescue dynamin assembly [75]. Therefore, it is likely that SH3/BAR proteins function as templates for dynamin at the necks of CCPs, generating the perfect curvature for the efficient recruitment of dynamin and subsequent assembly at the necks of CCPs.

\section{PH domain and $P I P_{2}$ binding}

The PH domain of dynamin binds to lipids, although dynamin recruitment to CCPs is independent of this interaction [24]. The PH domain inserts into the outer leaflet of the lipid bilayer via its variable loop 1, a property that enhances membrane fission $[76,77]$. Interestingly, the $\mathrm{PH}$ domains from different dynamin isoforms convey different lipid-binding properties [78]. Dynamin 2 (ubiquitous isoform) fails to bind larger liposomes unlike the neuronal isoform, dynamin 1 [75,78]. This difference in lipid binding is directly related to their $\mathrm{PH}$ domains [78]. Dynamin 1 and 2 share the same amino acid sequence in variable loop 1 but differ in one amino acid in variable loop 3 of the PH domain (Y600 versus L600). Switching these amino acids results in a reverse in the fission activity of the proteins. Generation of a dynamin 2 construct expressing the dynamin $1 \mathrm{PH}$ domain increases transferrin uptake, further indicating that lipid sensing by the PH domain is beneficial in the fission reaction [78]. These data suggest that membrane insertion and sensing are conveyed by the variable loop 1 and 3 respectively, and that both of these components are crucial for fission [76-78]. Also, the addition of endophilin to dynamin 2 "rescues" lipid binding and vesiculation from GUVs, further supporting a role for the SH3/BAR proteins as curvature-generating templates for dynamin [75].

The exact role of the PH domain is still elusive. It has been proposed that insertion of the $\mathrm{PH}$ domain into the membrane may act to modify the composition of the neck by sequestering $\mathrm{PIP}_{2}$ [79]. There is emerging evidence that BAR proteins also sequester $\mathrm{PIP}_{2}[80,81]$. Endophilin clusters $\mathrm{PIP}_{2}$ in GUVs [81] and binding to $\mathrm{PIP}_{2}$ has been shown to facilitate N-BAR protein-mediated curvature [82], suggesting that modulation of lipid composition (as well as curvature) plays a role in fission. In yeast, variation in the local concentration of $\mathrm{PIP}_{2}$ along the length of the CCP necks has been implicated in facilitating the actual fission reaction [43], but yeast lacks dynamin and, as of yet, local variation in the concentration of $\mathrm{PIP}_{2}$ has not 
been implicated in dynamin-mediated plasma membrane fission.

Taken together, the evidence suggests that amphiphysin and endophilin act as templates for dynamin recruitment and assembly at the necks of CCPs by providing optimal curvature and that they may be integral parts of a pre-fission complex to regulate the actual fission reaction. A potential role of such a complex may be to sequester $\mathrm{PIP}_{2}$ at the neck. Formation of a dynamin-SH3/ BAR pre-fission complex may also serve to regulate the GTPase activity of dynamin.

\section{Dynamin-mediated membrane fission GTP cycling and conformational changes}

Membrane fission requires dynamin-stimulated GTPase activity [71] that is promoted by $\mathrm{G}$ domain dimerization [83]. G domain dimerization stabilizes the transition state of the GTP hydrolysis reaction, a proposed key determinant for dynamin-mediated fission [84]. G domain dimerization only occurs between rungs of the dynamin helix and, therefore, stimulated hydrolysis only takes place in the assembled polymer when there is close opposition between rungs [84]. Therefore, the architecture of the dynamin polymer ensures that assembly and stimulated GTPase activity are tightly coupled. Stimulated GTP hydrolysis contributes to a conformation change in the dynamin polymer, the dynamin powerstroke, in which the three-helix bundle signaling element (BSE) swings down from the G domain core as a result of GTP hydrolysis [84]. It has been suggested that this powerstroke generates the force necessary to sever the membrane and may be responsible for the super-coiling and twisting of dynamindecorated tubes observed in vitro as a result of GTP hydrolysis [85-87].

The effect of GTP hydrolysis on the assembled dynamin polymer has been studied for many years. Dynamin assembles on liposomes and forms well-decorated tubes that constrict upon the addition of GTP [87]. These observations led to the postulation that dynamin acts as a mechanochemical enzyme that severs the membrane by force generated from GTP hydrolysis. Three-dimensional reconstructions of dynamin revealed that constriction is mediated by a kink in the stalk domain and assembling into a two-start helix $[84,88]$. In the presence of a nonhyrolyzable GTP analogue (GMPPCP) a dynamin mutant, lacking the C-terminal PRD $(\triangle \mathrm{PRD})$, decreases the inner luminal diameter of the lipid tube from $20 \mathrm{~nm}$ to $7 \mathrm{~nm}[84,85,89-91]$. More recently, it has been shown that a transition-state defective mutant, $\mathrm{K} 44 \mathrm{~A}$, trapped in a pre-fission state, constricts the inner lumen to $3.7 \mathrm{~nm}$, reaching the theoretical limit required for spontaneous membrane fission [88]. K44A dynamin mediates this "super-constriction" by adopting a two-start helical symmetry that allows more efficient packing of the dynamin subunits in the polymer. This super-constricted K44A dynamin is trapped in a ground state configuration, suggesting that GTP-binding promotes an initial conformational change in the polymer, prior to hydrolysis. In addition, half of the $\mathrm{PH}$ domains are tilted out of the membrane in the super-constricted state, compared to the non-constricted dynamin polymer. This suggests that, upon super-constriction, the PH domain re-arranges its orientation in the outer leaflet of the bilayer that may contribute to the destabilization of the lipid and act to promote fission. Also, in the super-constricted structure, the packing of the dynamin subunits is such that the number of $\mathrm{G}$ domain dimer interfaces is significantly higher than in an assembled one-start helix. G domain dimerization is required for stimulated GTPase activity and thus, it's reasonable to assume that a two-start helical symmetry is more favorable for fission. In support of this, wildtype dynamin also assembles into a two-start helix in the presence of GTP, and constricts the membrane to an inner luminal diameter of $\sim 4 \mathrm{~nm}$ [88].

In vitro, short scaffolds of dynamin polymers mediate fragmentation of lipid nanotubes in the presence of GTP [92-94]. Furthermore, it has been suggested that two rungs of a dynamin assembly act as a minimal fission machinery [95]. A recent TIRF (total internal reflection fluorescence) microscopy study shows that, in a majority of scission events observed in cells, the number of recruited dynamin molecules is $\sim 26$ [46]. Interestingly, this fits well with the number of dynamin molecules that are required for dynamin assembly around a lipid tube.

Exactly how the stimulated GTPase activity of dynamin aims to evoke fission is still unknown. However, it is reasonable to assume that dynamin assembly on the necks of CCPs is followed by a series of conformational changes, super-constriction, the BSE powerstroke, super-coiling and twisting, and re-arrangement of the $\mathrm{PH}$ domain, all regulated by the cycling of GTP. Despite recent insights into the structural features of dynamin at various nucleotide states, exactly how these conformational changes contribute to the fission reaction remains to be elucidated.

\section{Three mechanisms for dynamin-mediated plasma membrane fission}

Currently, three potential mechanisms have been put forward to describe the final dynamin-mediated fission event. Firstly, GTP-driven constriction and relaxation of the underlying membrane (as a result of assembly and disassembly of short dynamin scaffolds) causes the underlying membrane to be severed $[92,94]$. Secondly, the GTP-driven constriction of dynamin scaffolds generates 
torque that acts on areas of the membrane where the difference in curvature is greater (such as the edge of the dynamin scaffold) and the membrane is destabilized to promote fission [93]. Thirdly, PH domain re-arrangement or tilting in the assembled dynamin polymer results in deformation of the lipids, which generates enough energy to overcome the hemi-fission barrier [96]. Although these models are based on single-method studies, and thus each needs to be confirmed by additional techniques, they provide an excellent foundation for future studies. Also these models are most likely not mutually exclusive, and it is plausible that all of these factors work in combination with the GTP-dependent conformational changes described to promote fission. Although these in vitro assays show that dynamin alone can mediate fission, the element of regulation is removed, and hence further studies are necessary to mimic the in vivo environment containing accessory protein and local variations in nucleotide concentration and lipid composition.

\section{Regulation of the fission reaction by SH3/BAR proteins}

Dynamin co-assembles with both amphiphysin and endophilin in vitro and at late stages of endocytosis, indicating that these proteins may be involved in regulating the actual fission reaction [26,97]. The GTPase activity of dynamin is influenced by many factors, namely lipid binding, self-assembly and the binding of SH3 proteins to the PRD $[5,98-101]$. The localization of the
PRD within the assembled dynamin polymer is unclear. However, recent evidence suggests that the PRD localizes at the surface of the assembled dynamin polymer, in close proximity to the $\mathrm{G}$ domain [88]. Intriguingly, a conserved region of the $\mathrm{G}$ domain most proximal to the putative PRD location is only present in dynamin family members containing a PRD. The close proximity of this region of the $\mathrm{G}$ domain to the PRD suggests a possible physical link between the two domains. This indicates that SH3/ BAR proteins may influence the GTPase activity of the assembled dynamin polymer at late stages of endocytosis. Both amphiphysin and endophilin have been shown to influence the fission activity of dynamin in vitro [74,75]. Therefore, SH3/BAR proteins may act as curvatureinducing templates for dynamin at the necks of CCPs and, hence, either promote fission indirectly by generating optimal conditions for dynamin assembly and stimulated GTPase activity, or directly by interacting with the dynamin polymer during the fission reaction.

\section{Conclusions}

The dynamin-binding partners intersectin, endophilin and amphiphysin are crucial in regulating the function of dynamin during clathrin-mediated endocytosis (Figure 2). These proteins act throughout the process to facilitate dynamin-mediated fission and to specifically control the sequential steps of recruitment, assembly and stimulated GTPase activity of dynamin. These

Figure 2. The sequential steps of dynamin-mediated fission

\section{Recruitment Assembly Fission}

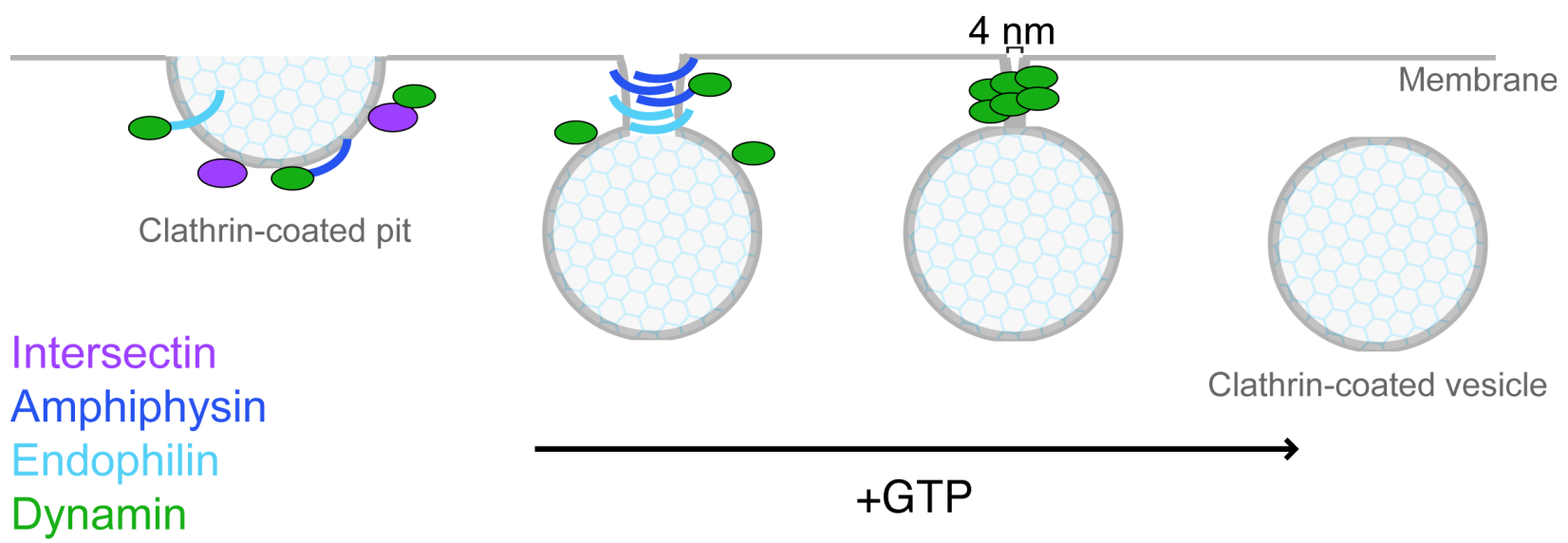

Dynamin's role in clathrin-mediated endocytosis migrates through the sequential steps of recruitment, assembly and fission. The SH3 domain-containing binding partners intersectin, amphiphysin and endophilin control these steps and thus promote dynamin-mediated fission. Intersectin acts as a scaffold for dynamin and other endocytic proteins, ensuring its recruitment to sites of endocytosis. Amphiphysin and endophilin are BIN/amphiphysin/Rvs (BAR) proteins and generate constriction of the clathrin-coated pit neck that promotes the dynamin assembly into a polymer. The assembled dynamin polymer undergoes GTP-dependent conformational changes that lead to super-constriction of the neck, the bundle signaling element (BSE) powerstroke, re-arrangement of the pleckstrin homology $(\mathrm{PH})$ domain and polymer disassembly all leading to plasma membrane fission. 
SH3-containing proteins act as scaffolds to bring dynamin to the sites of endocytosis in cells, and function as membrane templates at CCP necks to provide the optimal curvature for dynamin recruitment and assembly. They may also promote fission reaction by modulating the local lipid environment. Clues to the mechanisms of dynaminmediated fission have evolved in recent years, suggesting that assembly and subsequent conformational changes of short scaffolds, differential membrane curvatures, and tilting of the $\mathrm{PH}$ domain all contribute to membrane fission. Based on our current understanding as discussed in this review, future studies in vivo will help further elucidate the function of dynamin during the endocytic process in the cell. There are some questions remaining that will push our understanding of how dynamin mediates fission of the plasma membrane, and also how other members of the family operate. Exactly what is the composition of the minimal fission machinery in vivo? What is the role of the powerstroke and other potential conformational changes brought on by GTP hydrolysis? What is the role of the PH domain? Is fission an active or passive reaction?

Currently, the dynamin field is enjoying an influx of structural data, due to recent advances in the field of cryo-electron microscopy (cryo-EM) and major efforts in crystallography. A new generation of cameras that allow cryo-EM density maps to reach atomic resolution will surely result in a surge of structural information in the coming years and this will ultimately elucidate the intraand inter-molecular organization of the dynamin fission complex. Still, EM and crystallography alone are insufficient to track the dynamic process of fission. Continuous efforts to elucidate the structural characteristics of the dynamin fission machinery are key but must proceed in collaboration with functional studies. Several "live" fission assays have been published recently that shed light on the transient nature of the fission reaction. However groundbreaking, these are limited by the poor resolution of light and fluorescence microscopy, and thus fail to provide high-resolution information about the organization of the fission complex. Efforts to understand the role of dynamin in cells are relying heavily on protein overexpression, which in itself is problematic. A caveat to the multitude of techniques applied to study the fission reaction is the wide variety in lipid templates used. Fission requires the interplay between proteins and lipids, and the use of lipids must influence the setup and thus the interpretations of the data. Consensus must be reached in the efforts to infer mechanisms of fission in vivo from in vitro results. Hopefully, as we embark on a new and exciting era for structural biology, efforts to reconcile observations in different systems and to adopt multidisciplinary approaches will help us to finally unravel the enigmatic role of dynamin in plasma membrane fission.

\section{Abbreviations}

BAR, BIN/amphiphysin/Rvs; BSE, bundle signaling element; CCP, clathrin-coated pit; cryo-EM, cryo-electron microscopy; Drp1, dynamin-related protein 1; GUV, giant unilamellar vesicle; PIP $_{2}$, phosphatidylinositol 4, 5-bisphosphate; $\mathrm{PH}$, pleckstrin homology; $\mathrm{PRD}$, prolinerich domain.

\section{Disclosures}

The authors declare that they have no disclosures.

\section{References}

I. Doherty GJ, McMahon HT: Mechanisms of endocytosis. Annu Rev Biochem 2009, 78:857-902.

2. Praefcke, Gerrit J K, McMahon HT: The dynamin superfamily: universal membrane tubulation and fission molecules? Nat Rev Mol Cell Biol 2004, 5: 133-47.

3. Ferguson SM, De Camilli P: Dynamin, a membrane-remodelling GTPase. Nat Rev Mol Cell Biol 2012, I3:75-88.

4. Schmid SL, Frolov VA: Dynamin: functional design of a membrane fission catalyst. Annu Rev Cell Dev Biol 20I I, 27:79-105.

5. Zheng J, Cahill SM, Lemmon MA, Fushman D, Schlessinger J, Cowburn D: Identification of the binding site for acidic phospholipids on the pH domain of dynamin: implications for stimulation of GTPase activity. J Mol Biol 1996, 255:|4-2I.

6. Kwiatkowska $\mathrm{K}$ : One lipid, multiple functions: how various pools of $\mathrm{PI}(4,5) \mathrm{P}(2)$ are created in the plasma membrane. Cell Mol Life Sci 2010, 67:3927-46.

7. Di Paolo G, De Camilli P: Phosphoinositides in cell regulation and membrane dynamics. Nature 2006, 443:65I-7.

8. Martin TF: $\mathbf{P I}(4,5) P(2)$ regulation of surface membrane traffic. Curr Opin Cell Biol 2001, I 3:493-9.

9. Sun Y, Carroll S, Kaksonen M, Toshima JY, Drubin DG: PtdIns(4,5) P2 turnover is required for multiple stages during clathrinand actin-dependent endocytic internalization. J Cell Biol 2007, I 77:355-67.

10. McPherson PS: Regulatory role of $\mathrm{SH} 3$ domain-mediated protein-protein interactions in synaptic vesicle endocytosis. Cell Signal 1999, I 1:229-38.

II. Okamoto PM, Herskovits JS, Vallee RB: Role of the basic, prolinerich region of dynamin in Src homology 3 domain binding and endocytosis. J Biol Chem 1997, 272: I 1629-35.

12. Shpetner HS, Herskovits JS, Vallee RB: A binding site for $\mathbf{S H 3}$ domains targets dynamin to coated pits. J Biol Chem 1996, 27 I : | 3-6.

13. Simpson F, Hussain NK, Qualmann B, Kelly RB, Kay BK, McPherson PS, Schmid SL: SH3-domain-containing proteins function at distinct steps in clathrin-coated vesicle formation. Nat Cell Biol 1999, I: I 19-24.

14. Solomaha E, Szeto FL, Yousef MA, Palfrey HC: Kinetics of Src homology 3 domain association with the proline-rich domain of dynamins: specificity, occlusion, and the effects of phosphorylation. J Biol Chem 2005, 280:23।47-56.

15. Evergren E, Gad H, Walther K, Sundborger A, Tomilin N, Shupliakov O: Intersectin is a negative regulator of dynamin recruitment to the synaptic endocytic zone in the central synapse. J Neurosci 2007, 27:379-90.

16. Koh T, Verstreken P, Bellen HJ: Dapl60/intersectin acts as a stabilizing scaffold required for synaptic development and vesicle endocytosis. Neuron 2004, 43:193-205.

I7. Koh T, Korolchuk VI, Wairkar YP, Jiao W, Evergren E, Pan H, Zhou Y, Venken, Koen J T, Shupliakov O, Robinson IM, O'Kane CJ, Bellen HJ: 
EpsI5 and Dapl60 control synaptic vesicle membrane retrieval and synapse development. J Cell Biol 2007, 178:309-22.

\section{FlOOOPrime}

18. Marie B, Sweeney ST, Poskanzer KE, Roos J, Kelly RB, Davis GW: Dap 160/intersectin scaffolds the periactive zone to achieve high-fidelity endocytosis and normal synaptic growth. Neuron 2004, 43:207-19.

19. Winther, Åsa M E, Jiao W, Vorontsova O, Rees KA, Koh T, Sopova E, Schulze KL, Bellen HJ, Shupliakov O: The dynamin-binding domains of Dap I60/intersectin affect bulk membrane retrieval in synapses. J Cell Sci 2013, 126:1021-31.

20. Shupliakov O, Löw P, Grabs D, Gad H, Chen H, David C, Takei K, De Camilli P, Brodin L: Synaptic vesicle endocytosis impaired by disruption of dynamin-SH3 domain interactions. Science 1997, 276:259-63.

21. Wigge P, Köhler K, Vallis $Y$, Doyle CA, Owen D, Hunt SP, McMahon HT: Amphiphysin heterodimers: potential role in clathrin-mediated endocytosis. Mol Biol Cell 1997, 8:2003-I5.

22. Wigge $\mathrm{P}$, Vallis $\mathrm{Y}, \mathrm{McMahon} \mathrm{HT}$ : Inhibition of receptor-mediated endocytosis by the amphiphysin SH3 domain. Curr Biol 1997, 7:554-60.

23. Wigge $P, M c M a h o n ~ H T:$ The amphiphysin family of proteins and their role in endocytosis at the synapse. Trends Neurosci 1998, 21:339-44.

24. Vallis $Y$, Wigge P, Marks B, Evans PR, McMahon HT: Importance of the pleckstrin homology domain of dynamin in clathrinmediated endocytosis. Curr Biol 1999, 9:257-60.

25. Yoshida Y, Takei K: Stimulation of dynamin GTPase activity by amphiphysin. Meth Enzymol 2005, 404:528-37.

26. Sundborger A, Soderblom C, Vorontsova O, Evergren E, Hinshaw JE, Shupliakov O: An endophilin-dynamin complex promotes budding of clathrin-coated vesicles during synaptic vesicle recycling. I Cell Sci 20II, I24:133-43.

27. Mayer BJ: SH3 domains: complexity in moderation. J Cell Sci 200I, I | 4: I253-63.

28. Nguyen JT, Turck CW, Cohen FE, Zuckermann RN, Lim WA: Exploiting the basis of proline recognition by $\mathrm{SH} 3$ and $\mathrm{WW}$ domains: design of $\mathrm{N}$-substituted inhibitors. Science 1998, 282:2088-92.

29. Pechstein A, Shupliakov O, Haucke V: Intersectin I: a versatile actor in the synaptic vesicle cycle. Biochem Soc Trans 2010, 38:18I-6.

30. Sakaba T, Kononenko NL, Bacetic J, Pechstein A, Schmoranzer J, Yao L, Barth H, Shupliakov O, Kobler O, Aktories K, Haucke V: Fast neurotransmitter release regulated by the endocytic scaffold intersectin. Proc Natl Acad Sci USA 2013, I I0: 8266-7I.

\section{FlOOOPrime}

31. Tsyba L, Nikolaienko O, Dergai O, Dergai M, Novokhatska O, Skrypkina I, Rynditch A: Intersectin multidomain adaptor proteins: regulation of functional diversity. Gene 2011, 473:67-75.

32. Yamabhai M, Hoffman NG, Hardison NL, McPherson PS, Castagnoli L, Cesareni G, Kay BK: Intersectin, a novel adaptor protein with two Eps I 5 homology and five Src homology 3 domains. J Biol Chem 1998, 273:31401-7.

33. Pechstein A, Bacetic J, Vahedi-Faridi A, Gromova K, Sundborger A, Tomlin N, Krainer G, Vorontsova O, Schäfer JG, Owe SG, Cousin MA, Saenger W, Shupliakov O, Haucke V: Regulation of synaptic vesicle recycling by complex formation between intersectin I and the clathrin adaptor complex AP2. Proc Natl Acad Sci U.S.A 2010, I07:4206-II.

34. Humphries AC, Donnelly SK, Way M: Cdc42 and the Rho GEF intersectin-I collaborate with Nck to promote N-WASPdependent actin polymerisation. J Cell Sci 2014, I 27:673-85.

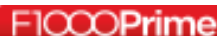

35. Klein IK, Predescu DN, Sharma T, Knezevic I, Malik AB, Predescu S: Intersectin-2L regulates caveola endocytosis secondary to Cdc42-mediated actin polymerization. J Biol Chem 2009, 284:25953-6I.

\section{FlOOOPrime
RECOMMENDED}

36. Cousin MA, Tan TC, Robinson PJ: Protein phosphorylation is required for endocytosis in nerve terminals: potential role for the dephosphins dynamin I and synaptojanin, but not AP I 80 or amphiphysin. J Neurochem 2001, 76:105-16.

37. Marks B, McMahon HT: Calcium triggers calcineurin-dependent synaptic vesicle recycling in mammalian nerve terminals. Curr Biol 1998, 8:740-9.

38. Slepnev VI, Ochoa GC, Butler MH, Grabs D, De Camilli P: Role of phosphorylation in regulation of the assembly of endocytic coat complexes. Science 1998, 281:82 I-4

39. Evergren E, Tomilin N, Vasylieva E, Sergeeva V, Bloom O, Gad H, Capani F, Shupliakov O: A pre-embedding immunogold approach for detection of synaptic endocytic proteins in situ. J Neurosci Methods 2004, I35: 169-74.

40. Aghamohammadzadeh S, Ayscough KR: Differential requirements for actin during yeast and mammalian endocytosis. Nat Cell Biol 2009, I I:1039-42.

\section{FlOOOPrime}

\section{RECOMMENDED}

4I. Ehrlich M, Boll W, van Oijen A, Hariharan R, Chandran K, Nibert ML, Kirchhausen $\mathrm{T}$ : Endocytosis by random initiation and stabilization of clathrin-coated pits. Cell 2004, I 1 8:59|-605.

\section{FlOOOPrime \\ RECOMMENDED}

42. Ferguson SM, Ferguson S, Raimondi A, Paradise S, Shen H, Mesaki K, Ferguson A, Destaing O, Ko G, Takasaki J, Cremona O, O'Toole E, De Camilli P: Coordinated actions of actin and BAR proteins upstream of dynamin at endocytic clathrin-coated pits. Dev Cell 2009, 17:81 |-22.

\section{FloOOPrime}

RECOMMENDED

43. Liu J, Sun Y, Drubin DG, Oster GF: The mechanochemistry of endocytosis. PLoS Biol 2009, 7 el 000204.

\section{FIOOOPrime
RECOMMENDED}

44. Merrifield C], Perrais D, Zenisek D: Coupling between clathrincoated-pit invagination, cortactin recruitment, and membrane scission observed in live cells. Cell 2005, I 21:593-606.

\section{FlOOOPrime}

RECOMMENDED

45. Cestra G, Toomre D, Chang S, Camilli P de: The Abl/Arg substrate ArgBP2/nArgBP2 coordinates the function of multiple regulatory mechanisms converging on the actin cytoskeleton. Proc Natl Acad Sci U.S.A 2005, I02: I73।-6.

46. Grassart A, Cheng AT, Hong SH, Zhang F, Zenzer N, Feng $Y$, Briner DM, Davis GD, Malkov D, Drubin DG: Actin and dynamin2 dynamics and interplay during clathrin-mediated endocytosis. J Cell Biol 2014, 205:721-35.

\section{FlOOOPrime
RECOMMENDED}

47. Taylor MJ, Lampe M, Merrifield CJ: A feedback loop between dynamin and actin recruitment during clathrin-mediated endocytosis. PLoS Biol 2012, 10 el001302.

\section{FlOOOPrime
RECOMMENDED}

48. Bauerfeind $R$, Takei $K$, Camilli $P$ de: Amphphysin I is associated with coated endocytic intermediates and undergoes stimulation-dependent dephosphorylation in nerve terminals. J Biol Chem 1997, 272:30984-92. 
49. Farsad K, Ringstad N, Takei K, Floyd SR, Rose K, De Camilli P: Generation of high curvature membranes mediated by direct endophilin bilayer interactions. J Cell Biol 200 I, I55:193-200.

50. Takei K, Slepnev VI, Haucke V, De Camilli P: Functional partnership between amphiphysin and dynamin in clathrin-mediated endocytosis. Nat Cell Biol 1999, 1:33-9.

51. Taylor MJ, Perrais D, Merrifield CJ: A high precision survey of the molecular dynamics of mammalian clathrin-mediated endocytosis. PLoS Biol 20II, 9 el 000604.

\section{FlOOOPrime}

52. Daumke $O$, Roux $A$, Haucke $V$ : BAR domain scaffolds in dynamin-mediated membrane fission. Cell 2014, I56:882-92.

\section{FlOOOPrime}

\section{RECOMMENDED}

53. Frost A, Unger VM, De Camilli P: The BAR domain superfamily: membrane-molding macromolecules. Cell 2009, I37:19|-6.

\section{FlOOOPrime}

54. Gallop JL, McMahon HT: BAR domains and membrane curvature: bringing your curves to the BAR. Biochem Soc Symp 2005, 223-31.

\section{FlOOOPrime}

55. Bhatia VK, Madsen KL, Bolinger $P$, Kunding A, Hedegård $P$, Gether U, Stamou D: Amphipathic motifs in BAR domains are essential for membrane curvature sensing. EMBO J 2009, 28:3303-I4.

\section{FlOOOPrime}

56. Frost A, Perera R, Roux A, Spasov K, Destaing O, Egelman EH, De Camilli $P$, Unger VM: Structural basis of membrane invagination by F-BAR domains. Cell 2008, I32:807-17.

\section{FIOOOPrime}

57. Gallop JL, Jao CC, Kent HM, Butler P, Jonathan G, Evans PR, Langen R, McMahon HT: Mechanism of endophilin N-BAR domainmediated membrane curvature. EMBO J 2006, 25:2898-9I0.

\section{FlOOOPrime} RECOMMENDED

58. Itoh T, De Camilli P: BAR, F-BAR (EFC) and ENTH/ANTH domains in the regulation of membrane-cytosol interfaces and membrane curvature. Biochim Biophys Acta 2006, I76I: 897-912.

59. Masuda M, Takeda S, Sone M, Ohki T, Mori H, Kamioka $Y$, Mochizuki N: Endophilin BAR domain drives membrane curvature by two newly identified structure-based mechanisms. EMBO J 2006, 25:2889-97.

60. Peter BJ, Kent HM, Mills IG, Vallis Y, Butler P, Jonathan G, Evans PR, McMahon HT: BAR domains as sensors of membrane curvature: the amphiphysin BAR structure. Science 2004, 303:495-9.

\section{FlOOOPrime}

\section{RECOMMENDED}

61. Suetsugu S: The proposed functions of membrane curvatures mediated by the BAR domain superfamily proteins. J Biochem 2010, 148:1-12.

62. Zhao $H$, Pykäläinen $A$, Lappalainen P: I-BAR domain proteins: linking actin and plasma membrane dynamics. Curr Opin Cell Biol 20I I, 23:|4-2I.

63. Itoh T, Erdmann KS, Roux A, Habermann B, Werner H, De Camilli P: Dynamin and the actin cytoskeleton cooperatively regulate plasma membrane invagination by BAR and F-BAR proteins. Dev Cell 2005, 9:79|-804
64. Wang O, Navarro, Marcos V A S, Peng G, Molinelli E, Goh SL, Judson BL, Rajashankar KR, Sondermann H: Molecular mechanism of membrane constriction and tubulation mediated by the F-BAR protein Pacsin/Syndapin. Proc Natl Acad Sci U.S.A 2009, 106:12700-5.

65. Henne WM, Boucrot E, Meinecke M, Evergren E, Vallis Y, Mittal R, McMahon HT: FCHo proteins are nucleators of clathrinmediated endocytosis. Science 2010, 328: | 28|-4.

\section{FlOOOPrime
RECOMMENDED}

66. Kamioka Y, Fukuhara S, Sawa H, Nagashima K, Masuda M, Matsuda M, Mochizuki N: A novel dynamin-associating molecule, forminbinding protein 17, induces tubular membrane invaginations and participates in endocytosis. J Biol Chem 2004, 279:4009I-9.

\section{FlOOOPrime}

\section{RECOMMENDED}

67. Ford, Marijn G J, Mills IG, Peter BJ, Vallis Y, Praefcke, Gerrit J K Evans PR, McMahon HT: Curvature of clathrin-coated pits driven by epsin. Nature 2002, 419:36I-6.

\section{FlOOOPrime}

\section{RECOMMENDED}

68. Legendre-Guillemin V, Wasiak S, Hussain NK, Angers A McPherson PS: ENTH/ANTH proteins and clathrin-mediated membrane budding. J Cell Sci 2004, I I7:9-18.

69. McMahon HT: Endocytosis: an assembly protein for clathrin cages. Curr Biol 1999, 9:R332-5.

70. Roux A, Koster G, Lenz M, Sorre B, Manneville J, Nassoy P, Bassereau P: Membrane curvature controls dynamin polymerization. Proc Natl Acad Sci U.S.A 2010, 107:4I4I-6.

7I. Damke H, Baba T, Warnock DE, Schmid SL: Induction of mutant dynamin specifically blocks endocytic coated vesicle formation. J Cell Biol 1994, I 27:915-34.

72. Takei K, McPherson PS, Schmid SL, De Camilli P: Tubular membrane invaginations coated by dynamin rings are induced by GTP-gamma $\mathbf{S}$ in nerve terminals. Nature 1995 , 374:186-90.

73. Andersson F, Löw P, Brodin L: Selective perturbation of the BAR domain of endophilin impairs synaptic vesicle endocytosis. Synapse 2010, 64:556-60.

\section{FOOOPrime
RECOMMENDED}

74. Meinecke M, Boucrot E, Camdere G, Hon W, Mittal R, McMahon HT: Cooperative recruitment of dynamin and BIN/amphiphysin/ Rvs (BAR) domain-containing proteins leads to GTP-dependent membrane scission. J Biol Chem 20I3, 288:665I-6I.

\section{FlOOOPrime
RECOMMENDED}

75. Neumann S, Schmid SL: Dual role of BAR domain-containing proteins in regulating vesicle release catalyzed by the GTPase, dynamin-2. J Biol Chem 2013, 288:25 I 19-28.

\section{FIOOOPrime}

76. Ramachandran R, Schmid SL: Real-time detection reveals that effectors couple dynamin's GTP-dependent conformational changes to the membrane. EMBO J 2008, 27:27-37.

FloOOPrime

77. Ramachandran R, Pucadyil T], Liu Y, Acharya S, Leonard M, Lukiyanchuk V, Schmid SL: Membrane insertion of the pleckstrin homology domain variable loop I is critical for dynamincatalyzed vesicle scission. Mol Biol Cell 2009, 20:4630-9.

\section{FlOOOPrime}

\section{RECOMMENDED}

78. Liu Y, Neumann S, Ramachandran R, Ferguson SM, Pucadyil TJ, Schmid SL: Differential curvature sensing and generating 
activities of dynamin isoforms provide opportunities for tissue-specific regulation. Proc Natl Acad Sci U.S.A 20II, I08: E234-42.

\section{FlOOOPrime}

\section{RECOMMENDED}

79. Bethoney KA, King MC, Hinshaw JE, Ostap EM, Lemmon MA: A possible effector role for the pleckstrin homology (PH) domain of dynamin. Proc Natl Acad Sci U.S.A 2009, 106:13359-64.

80. Saarikangas J, Zhao H, Pykäläinen A, Laurinmäki P, Mattila PK, Kinnunen, Paavo K J, Butcher SJ, Lappalainen P: Molecular mechanisms of membrane deformation by I-BAR domain proteins. Curr Biol 2009, 19:95-107.

\section{FlOOOPrime} RECOMMENDED

81. Zhao H, Michelot A, Koskela EV, Tkach V, Stamou D, Drubin DG, Lappalainen P: Membrane-sculpting BAR domains generate stable lipid microdomains. Cell Rep 2013, 4:1213-23.

\section{FlOOOPrime}

\section{RECOMMENDED}

82. Yoon $Y$, Zhang X, Cho W: Phosphatidylinositol 4,5-bisphosphate (Ptdlns $(4,5) P 2)$ specifically induces membrane penetration and deformation by Bin/amphiphysin/Rvs (BAR) domains. J Biol Chem 20I2, 287:34078-90.

\section{FIOOOPRime}

83. Chappie JS, Acharya S, Leonard M, Schmid SL, Dyda F: G domain dimerization controls dynamin's assembly-stimulated GTPase activity. Nature 2010, 465:435-40.

\section{FlOOOPrime}

84. Chappie JS, Mears JA, Fang S, Leonard M, Schmid SL, Milligan RA, Hinshaw JE, Dyda F: A pseudoatomic model of the dynamin polymer identifies a hydrolysis-dependent powerstroke. Cell 2011, 147:209-22.

\section{FlOOOPrime}

\section{RECOMMENDED}

85. Danino D, Moon K, Hinshaw JE: Rapid constriction of lipid bilayers by the mechanochemical enzyme dynamin. J Struct Biol 2004, 147:259-67.

86. Roux A, Uyhazi K, Frost A, De Camilli P: GTP-dependent twisting of dynamin implicates constriction and tension in membrane fission. Nature 2006, 44I:528-3I.

\section{FlOOOPrime}

87. Sweitzer SM, Hinshaw JE: Dynamin undergoes a GTP-dependent conformational change causing vesiculation. Cell 1998, 93:1021-9.

88. Sundborger AC, Fang S, Heymann JA, Ray P, Chappie JS, Hinshaw JE: A Dynamin Mutant Defines a Superconstricted Prefission State. Cell Reports 20I4, 8:734-742.



89. Chen $Y$, Zhang P, Egelman EH, Hinshaw JE: The stalk region of dynamin drives the constriction of dynamin tubes. Nat Struct Mol Biol 2004, I I:574-5.

\section{FlOOOPrime}

\section{RECOMMENDED}

90. Mears JA, Ray P, Hinshaw JE: A corkscrew model for dynamin constriction. Structure 2007, 15:1190-202.

91. Zhang P, Hinshaw JE: Three-dimensional reconstruction of dynamin in the constricted state. Nat Cell Biol 200I, 3:922-6.

92. Bashkirov PV, Akimov SA, Evseev Al, Schmid SL, Zimmerberg J, Frolov VA: GTPase cycle of dynamin is coupled to membrane squeeze and release, leading to spontaneous fission. Cell 2008, I35: 1276-86.

\section{FlOOOPrime}

93. Morlot S, Galli V, Klein M, Chiaruttini N, Manzi J, Humbert F, Dinis L, Lenz M, Cappello G, Roux A: Membrane shape at the edge of the dynamin helix sets location and duration of the fission reaction. Cell 2012, 151:619-29.

\section{FlOOOPrime} RECOMMENDED

94. Pucadyil TJ, Schmid SL: Real-time visualization of dynamincatalyzed membrane fission and vesicle release. Cell 2008, 135:1263-75

\section{FlOOOPrime}

\section{RECOMMENDED}

95. Liu Y, Mattila J, Schmid SL: Dynamin-catalyzed membrane fission requires coordinated GTP hydrolysis. PLoS ONE 2013, 8 e5569।.

96. Shnyrova AV, Bashkirov PV, Akimov SA, Pucadyil TJ, Zimmerberg J, Schmid SL, Frolov VA: Geometric catalysis of membrane fission driven by flexible dynamin rings. Science 2013, 339:1433-6.

\section{FlOOOPrime}

\section{RECOMMENDED}

97. Farsad K, Ringstad N, Takei K, Floyd SR, Rose K, De Camilli P: Generation of high curvature membranes mediated by direct endophilin bilayer interactions. J Cell Biol 200 I, I55:193-200.

98. Barylko B, Binns D, Lin KM, Atkinson MA, Jameson DM, Yin HL, Albanesi JP: Synergistic activation of dynamin GTPase by Grb2 and phosphoinositides. J Biol Chem 1998, 273:379I-7.

99. Barylko B, Wang L, Binns DD, Ross JA, Tassin TC, Collins KA Jameson DM, Albanesi JP: The proline/arginine-rich domain is a major determinant of dynamin self-activation. Biochemistry 2010, 49:10592-4.

100. Herskovits JS, Shpetner HS, Burgess CC, Vallee RB: Microtubules and Src homology 3 domains stimulate the dynamin GTPase via its C-terminal domain. Proc Natl Acad Sci U.S.A 1993, 90:1 1 468-72

10I. Warnock DE, Hinshaw JE, Schmid SL: Dynamin self-assembly stimulates its GTPase activity. J Biol Chem 1996, 27 I:223 I0-4. 